\title{
Massive Pericardial Effusion in a Patient with Hashimoto's Thyroiditis: Histological Examination of Underlying Cardiomyopathy
}

\author{
Takahiro Yamada, Hiroshi Yamamoto*, Kenji HiraharA* and Osamu ToKunAgA
}

\begin{abstract}
An unusual case of a hypothyroid patient with huge pericardial effusion due to Hashimoto's thyroiditis is reported. Cardiac tamponade occurred during admission. Eight hundred milliliters of pericardial effusion was withdrawn by pericardiocentesis. Even after successful replacement of thyroid hormone, she had recurrent effusion two years later. Refractory pericardial effusion is a rare complication in treated hypothyroid patients. Underlying cardiomyopathy was presented with hemodynamic and histological examinations.
\end{abstract}

(Internal Medicine 34: 1-5, 1995)

Key words: hypothyroidism, myxedema, cardiac tamponade

\section{Introduction}

Cardiovascular manifestations in hypothyroidism include pericardial effusion $(1,2)$, cardiomyopathy $(1,3-5)$, accelerated atherosclerosis $(1,6,7)$ and hypertension (1). Pericardial effusion caused by hypothyroidism is demonstrated by echocardiogram in as many as $30 \%$ of patients (8), however, a large amount of effusion is rare and associated cardiac tamponade is extremely rare; to our knowledge, only 22 reports of this disorder appear in the English literature (7, 9-14). Among them, precise hemodynamic data were described in two papers $(11,14)$, and histological observation was made in two reports $(7,13)$.

\section{Case Report}

A 61-year-old woman, who had a history of systemic hypertension, was admitted to a hospital on May 30, 1989, with complaints of fatigue, dyspnea, palpitation, alopecia, dry skin, systemic edema and weakness of muscle strength.

On physical examination, blood pressure was $150 / 70 \mathrm{mmHg}$ without paradox; pulse, 62 beats $/ \mathrm{min}$; temperature, $37.3^{\circ} \mathrm{C}$. Thyroid gland was not palpable. Her heart sounds were faint without murmurs. There was nonpitting edema on face and legs. Muscle strength of extremities was weak associated with Gowers' sign. Muscle atrophy was absent. Deep tendon reflexes were generally diminished.

Laboratory data were as follows: $\mathrm{Hb}, 12.4 \mathrm{~g} / \mathrm{dl}$; hematocrit,
$36.4 \%$; red cell count, $4.1 \times 10^{6} / \mathrm{mm}^{3}$; white count, $18,800 / \mathrm{mm}^{3}$; erythrocyte sedimentation rate, $12 \mathrm{~mm} / 1 \mathrm{~h}$; the test for Creactive protein, negative; serum sodium, $148 \mathrm{mEq} / \mathrm{l}$; potassium, $2.1 \mathrm{mEq} / 1$; chloride, $101 \mathrm{mEq} / \mathrm{l}$; serum aspartate aminotransferase, $537 \mathrm{IU} / \mathrm{l}$, alanine aminotransferase, $138 \mathrm{IU} / \mathrm{l}$; lactate dehydrogenase, 5,179 IU/1; creatinine phosphokinase, 637 $\mathrm{IU} / \mathrm{l}(\mathrm{MM}=99 \%, \mathrm{MB}=1 \%)$; and total cholesterol, $373 \mathrm{mg} / \mathrm{dl}$. Cortisol level at A.M. was $33.5 \mu \mathrm{g} / \mathrm{dl}$ (normal, 2.7-15.5 $\mu \mathrm{g} / \mathrm{dl}$ ). 17 -ketosteroid in urine was $1.51 \mathrm{mg} / \mathrm{day}$. The values of adrenocorticotropic hormone and growth hormone were normal.

Function tests of the thyroid showed a severe hypothyroidism with $0.8 \mu \mathrm{g} / \mathrm{dl}$ of serum L-thyroxine $\left(\mathrm{T}_{4}\right)$ (normal, $4.5-12.3 \mu \mathrm{g} /$ $\mathrm{dl}$ ), unmeasurable triiodo-L-thyronine $\left(\mathrm{T}_{3}\right)$ (normal, 0.7-2.1 $\mathrm{ng} / \mathrm{ml}$ ) and $38.99 \mu \mathrm{IU} / \mathrm{ml}$ of thyroid-stimulating hormone (TSH) level (normal, $0.24-3.70 \mu \mathrm{IU} / \mathrm{ml}$ ). High titers of antimicrosomal antibodies $(\times 204,800$, normal: $<\times 100)$ were noted. The test for antithyroglobulin antibodies was negative.

Electrocardiogram showed low voltage in the limb leads and generalized flattening of the ST-T segment; ST depression was found in II, III, aVf and V5 (Fig. 1a). Electrocardiogram on the second admission (Fig. 1b) showed no displacement of ST segments characteristic for ischemic heart disease. The voltage of QRS complexes was increased after treatment of Ltriiodothyronine (Fig. 1b). A chest X-ray film revealed a globular-shaped cardiopericardial silhouette, moderate left pleural effusion, and marked vascular congestion with Kerley B lines on the right (Fig. 2). Massive pericardial effusion associated

From the Department of Pathology, Saga Medical School, Saga and Yamamoto Hospital*, Imari

Received for publication October 25, 1993; Accepted for publication August 17, 1994

Reprint requests should be addressed to Dr. Takahiro Yamada, the Department of Pathology, Saga Medical School, Saga 849 


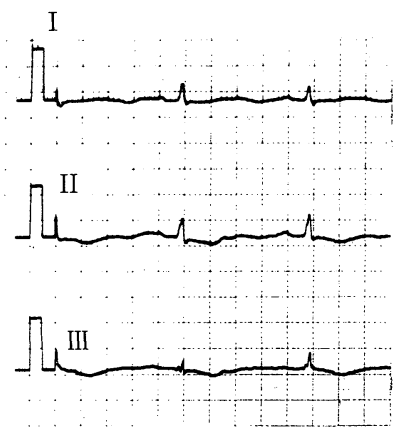

$\mathrm{aV} V_{R}$
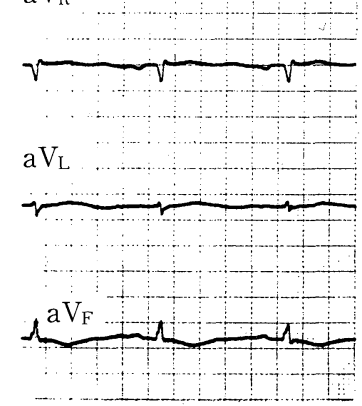

a

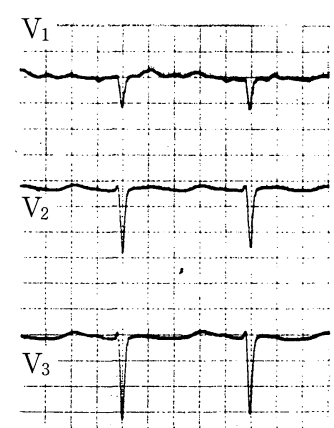

$\mathrm{V}_{4}$
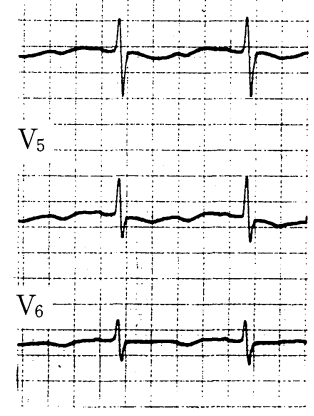

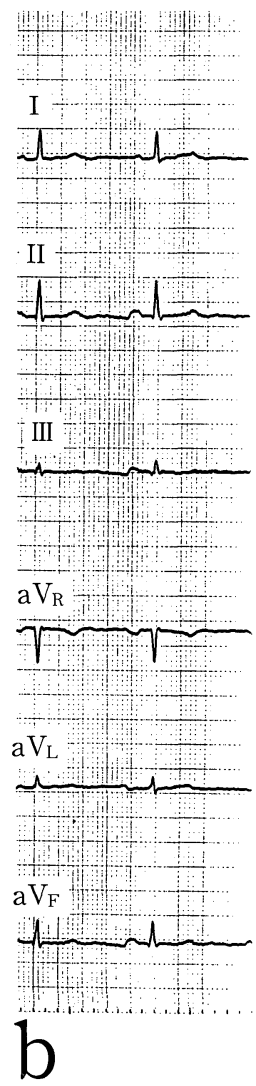

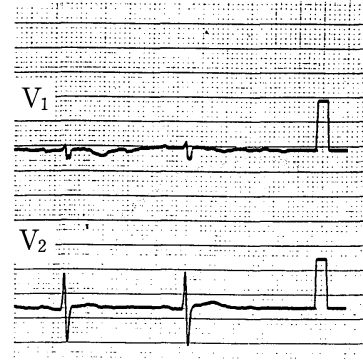
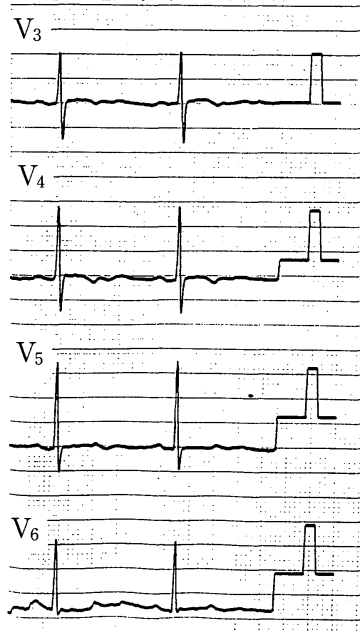

Fig. 1. Electrocardiograms of first admission (a) and second admission (b). Note an increase of voltage of QRS complexes.

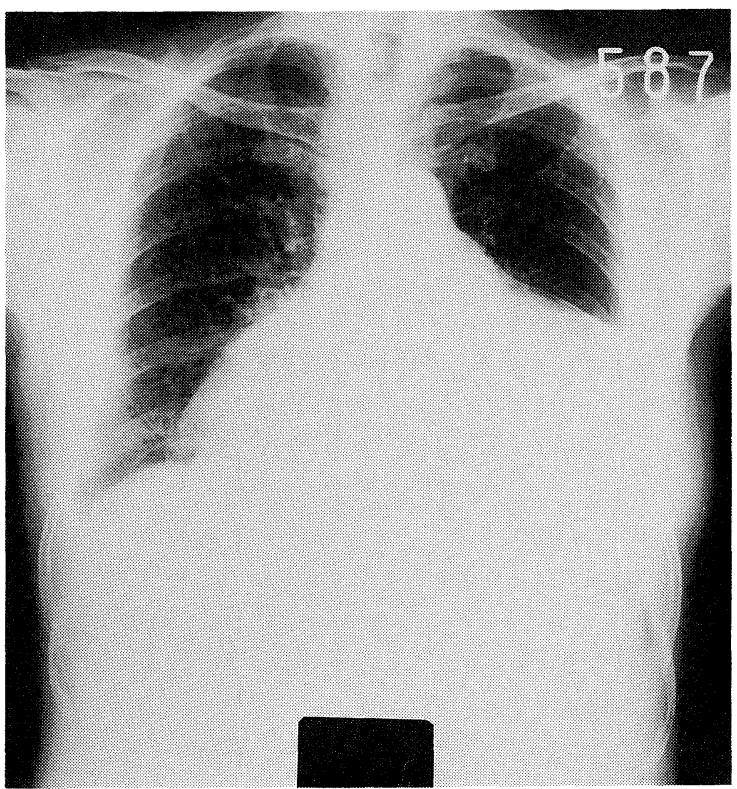

Fig. 2. Chest radiograph showing gross cardiomegaly.

with mild pleural effusion and ascites was demonstrated by echocardiographic and computed tomographic technique (Fig. 3). Liver congestion was not evident. Right-heart catheteriza- tion revealed impaired hemodynamics (Table 1).

Eight hundred milliliters of pericardial effusion was withdrawn by pericardiocentesis, and the removed fluid was examined for cytological, chemical and bacterial analysis. Mesothelial cells were the only cellular element; there were neither inflammatory cells nor malignant cells. Culture for bacteria including acid-fast bacilli was negative. Total protein was $5.2 \mathrm{~g} / \mathrm{dl}$. Evaluation of cholesterol was not performed. Two days after the pericardiocentesis, cardiac function was improved and the PCW was down to $0 \mathrm{mmHg}$ (mean) (Table 1).

Under the diagnosis of hypothyroidism due to Hashimoto's thyroiditis and associated heart failure, the patient was started on a prescription of L-triiodothyronine $50 \mu \mathrm{g} /$ day per os (P.O.) and digoxin $0.25 \mathrm{mg} /$ day P.O. The L-triiodothyronine was finally increased to $75 \mu \mathrm{g} /$ day. Two months later, her physical conditions improved and became symptomless. Serum $\mathrm{T}_{4}$ and $\mathrm{T}_{3}$ were $7.8 \mu \mathrm{g} / \mathrm{dl}$ and $0.98 \mathrm{ng} / \mathrm{ml}$, respectively. However, TSH still remained at the high level of $36.88 \mu \mathrm{IU} / \mathrm{ml}$. Other laboratory data were within normal limit. Two years later, she had recurrent pericardial effusion and dilatation of right and left ventricles. Data of right-heart catheterization is shown in Table 2. Coronary arteriogram demonstrated no stenotic lesions (Fig. 4). The left ventricle was mildly dilated (Fig. 5). Myocardial biopsy was carried out from the right ventricle and the tissue fragments were fixed in $10 \%$ formalin for light microscopic observation. The endocardium was thickened by accumulation 


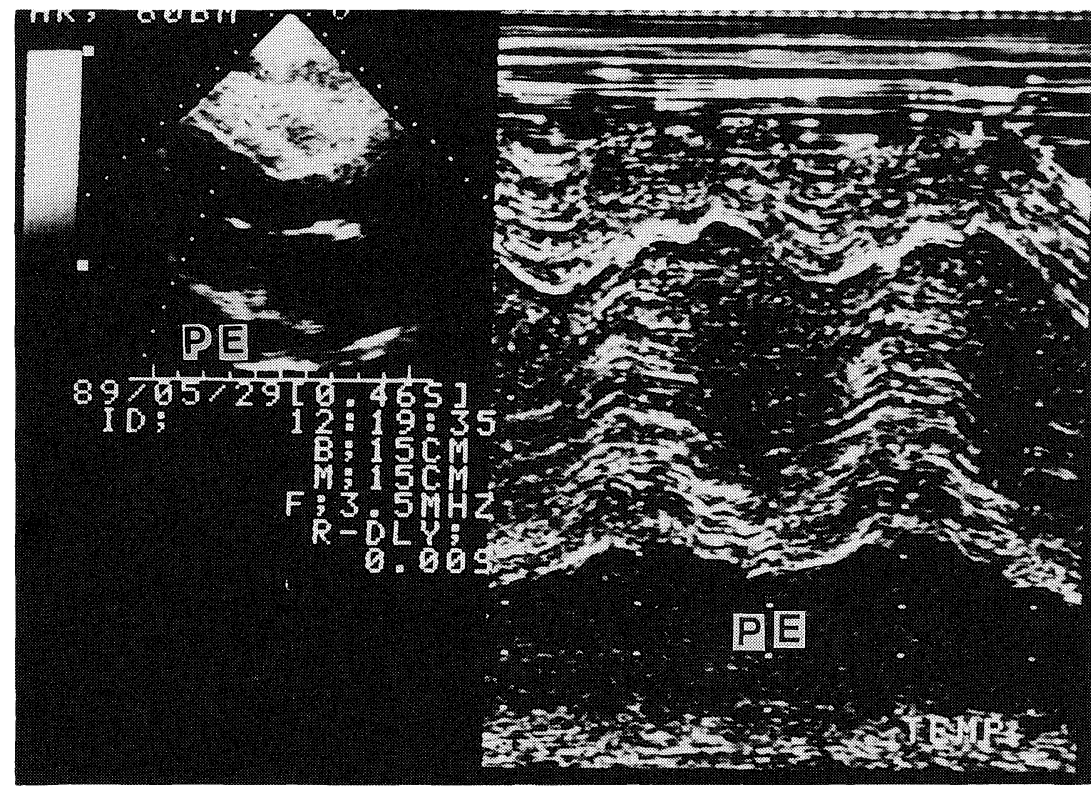

Fig. 3. Echocardiogram of the heart lying in a large pericardial effusion (PE). Note pendicular motion of septal and posterior walls. Free wall of left ventricle: $20 \mathrm{~mm}$, septum: $18 \mathrm{~mm}$.

Table 1. Hemodynamic Values of before and after Pericardiocentesis

\begin{tabular}{|c|c|c|c|c|}
\hline & \multicolumn{2}{|c|}{ Before pericardiocentesis } & \multicolumn{2}{|c|}{ After pericardiocentesis } \\
\hline & Systole/Diastole & Mean (EDP) & Systole/Diastole & Mean (EDP) \\
\hline RA & $13 / 8$ & 9 & $4 /-1$ & 3 \\
\hline RV & $29 / 0$ & (15) & $20 / 0$ & (8) \\
\hline MPA & $31 / 18$ & 24 & $18 / 7$ & 12 \\
\hline PAW & $20 / 17$ & 18 & $1 / 0$ & (0) \\
\hline $\mathrm{CO}(\mathrm{CI})$ & \multicolumn{2}{|c|}{$2.19(1.50)$} & \multicolumn{2}{|c|}{$4.22(2.89)$} \\
\hline EDVI & \multicolumn{2}{|c|}{41.78} & \multicolumn{2}{|c|}{47.95} \\
\hline ESVI & \multicolumn{2}{|c|}{20.55} & \multicolumn{2}{|c|}{17.12} \\
\hline EF & \multicolumn{2}{|c|}{0.50} & \multicolumn{2}{|c|}{0.64} \\
\hline
\end{tabular}

RA: right atrium (mmHg), $\mathrm{RV}$ : right ventricle ( $\mathrm{mmHg}$ ), MPA: main pulmonary artery $(\mathrm{mmHg})$, PAW: pulmonary artery wedge $(\mathrm{mmHg}), \mathrm{CO}$ : cardiac output $(\mathrm{L} / \mathrm{min}), \mathrm{CI}$ : cardiac index $\left(\mathrm{L} / \mathrm{min} / \mathrm{m}^{2}\right)$, EDVI: end diastolic volume index ( $\mathrm{ml} /$ $\left.\mathrm{m}^{2}\right)$, ESVI: end systolic volume index $\left(\mathrm{ml} / \mathrm{m}^{2}\right)$, EF: ejection fraction $(\%)$, EDP: end diastolic pressure.

of mucinous ground substance with sparsely textured spindle cells (Fig. 6). Myofibers showed attenuation and focal vacuolation. Basophilic mucoid degeneration of the myofibers was not evident. The interstitium was in part wide due to the collection of mucoid material and fat infiltration. Mild infiltration of lymphoid cells was seen.
Table 2. Right-Heart Catheterization in Second Admission

\begin{tabular}{ccc}
\hline & Systole/Diastole & Mean (EDP) \\
\hline RA & $8 / 0$ & 2 \\
RV & $24 / 0$ & $(9)$ \\
MPA & $21 / 6$ & 12 \\
PAW & $5 / 0$ & 2 \\
CO (CI) & & $6.39(4.38)$ \\
\hline
\end{tabular}

RA: right atrium (mmHg), RV: right ventricle $(\mathrm{mmHg})$, MPA: main pulmonary artery (mmHg), PAW: pulmonary artery wedge $(\mathrm{mmHg}), \mathrm{CO}$ : cardiac output $(\mathrm{L} / \mathrm{min}), \mathrm{CI}$ : cardiac index $\left(\mathrm{L} / \mathrm{min} / \mathrm{m}^{2}\right)$, EDP: end diastolic pressure $(\mathrm{mmHg})$.

\section{Discussion}

In the majority of hypothyroid patients with pericardial effusion, the pericardium is histologically normal. However, in patients with a large quantity of effusion, cholesterol pericarditis is a well-known phenomenon. It is not always specific for hypothyroidism $(15,16)$, histologically characterized by the infiltration of mononuclear cells, crystallization of cholesterol, giant cell formation and fibrous thickening $(1,7,13)$, which may reduce a distensibility of the pericardium leading to cardiac tamponade. The cholesterol crystals incite a vigorous cellular reaction following fluid overexudation and pericardial thickening. Chronic accumulation of the fluid and diminished 

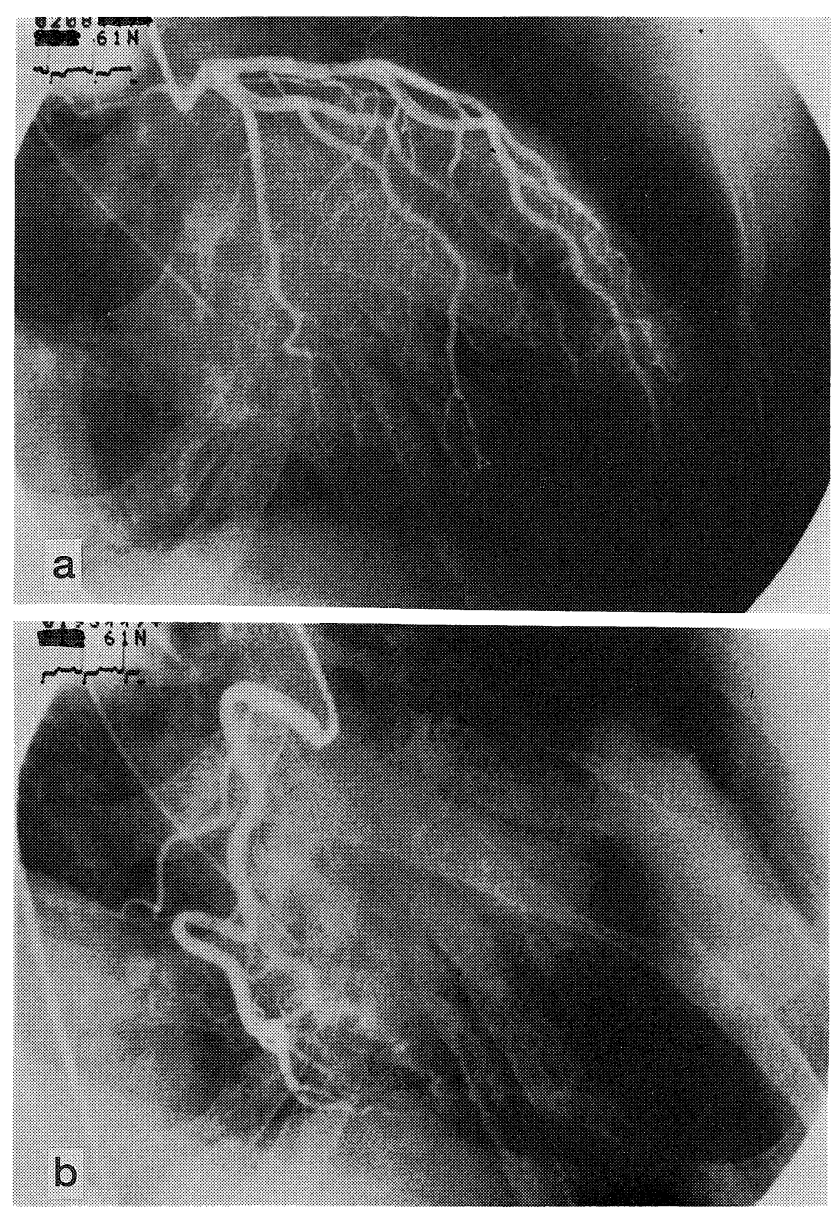

Fig. 4. Left (a) and right (b) coronary arteriograms showing no stenosis.

reabsorption of cholesterol might increase its concentration, and allow precipitation and crystallization of cholesterol. However, the pathogenesis has not been fully understood.

In hypothyroid patients, cardiac output was markedly reduced, and the mean decrease from normal individuals was reported at $47 \%$ (17), however, associated cardiogenic shock was rare (18). Echocardiographic evaluation and follow-up examination of untreated hypothyroid patients demonstrates reversible cardiomyopathy including asymmetric septal hypertrophy, reduced amplitude of systolic septal excursion, reduced percent of systolic septal thickening, reduced dimension of the left ventricular outflow tract and systolic anterior motion of the mitral valve (5). Although microscopic changes in the myocardium warranting a diagnosis of "myxedema heart" are not found, the histologic pictures most frequently recognized are swelling of myocardial cells, vacuolation, degeneration of fibers, fatty infiltration and interstitial edema $(1,4)$. Since, most hypothyroid patients with cardiac tamponade were not fatal and recovered with pericardiocentesis and administration of thyroid hormone $(9-12,14)$, only a few reports included a histopathological investigation $(7,14)$. The epicardium and the coronary arteries were more vulnerable sites than the myocardium and endocardium. The coronary arteries showed luminal

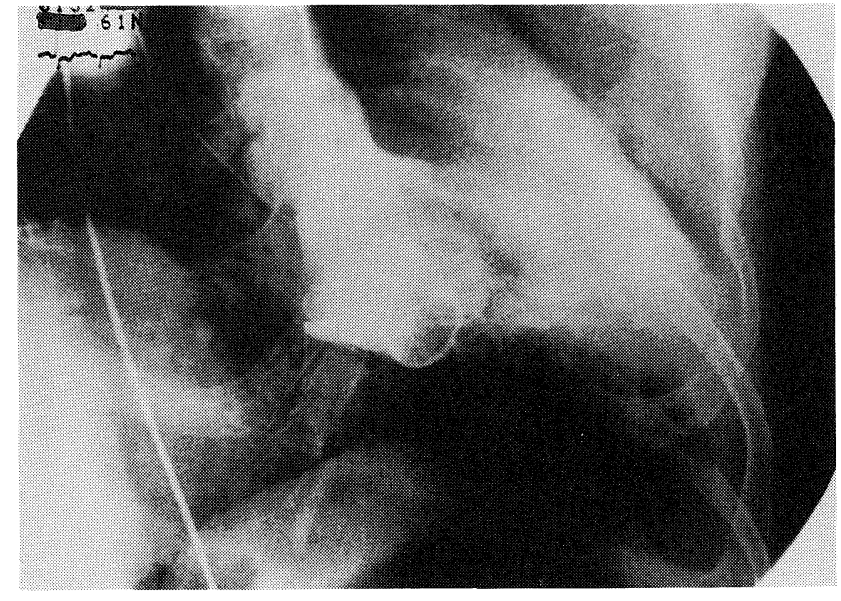

Fig. 5. Left ventriculogram in diastole. Right anterior oblique view. Note mild dilatation of the ventricle.

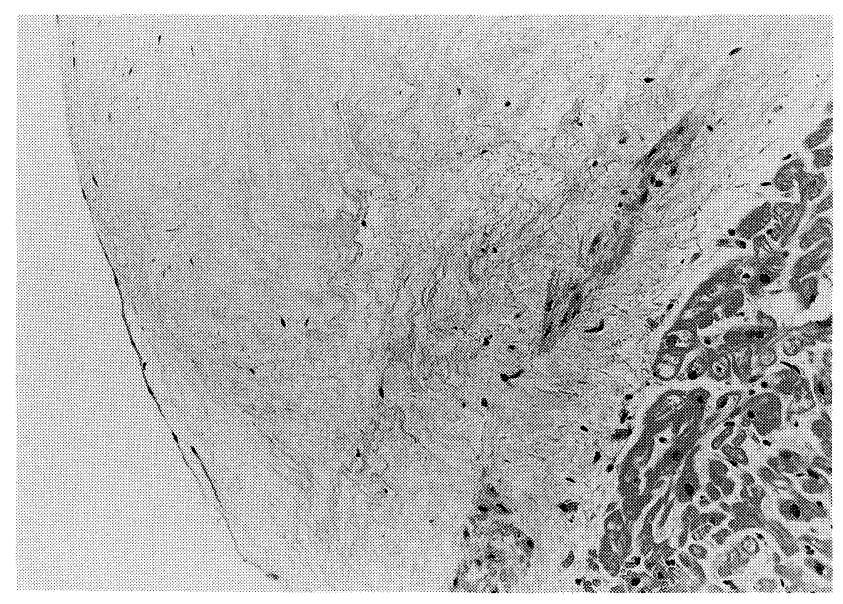

Fig. 6. Light micrograph of the endocardium and myocardium showing thickening of the endocardium due to accumulation of mucinous ground substance (HE stain, $\times 170$ ).

stenosis by accelerated atherosclerosis. The development of coronary atherosclerosis was highly associated with hypertension and hypercholesterolemia which were frequently encountered in hypothyroidism.

In the present case, clinical manifestations suggesting cardiac tamponade involved dyspnea, faint heart sound, diminished cardiac output and systemic venous congestion associated with liver dysfunction. The fluid accumulation was considered to be caused by hypothyroidism; tuberculous and carcinomatous pericarditis could be ruled out based on the cytology and culture of the fluid. Cardiac infarction-associated pericarditis was also excluded by coronary angiography. In addition, histological examination of the myocardium supports in part the cardiomyopathy observed in myxedema. Cardiac function was remarkably improved after pericardiocentesis. However, persistent dilatation of the right and left ventricles was demonstrated with echocardiogram and angiogram over the four-year 


\section{Huge Pericardial Effusion in Myxedema}

follow-up period. Underlying cardiomyopathy should be strongly suspected in hypothyroid patients with persistent dilated ventricles and low ejection fraction. The chronic cardiac failure could accelerate fluid accumulation and diminish reabsorption as a result of venous congestion.

\section{References}

1) McAllister HA Jr. Cardiovascular Pathology, Silver MD, Ed. New York, Edinburgh, London, Melbourne, 1983, p. 1038.

2) Kerber RE, Sherman B. Echocardiographic evaluation of pericardial effusion in myxedema. Circulation 52: 823, 1975.

3) Hamilton JD, Greenwood WF. Myxedema heart disease. Circulation 15: $442,1957$.

4) Ikram H. The cardiac manifestations of hypothyroidism. Curr Med Drugs 8: $11,1967$.

5) Santos AD, Miller RP, Mathew PK, Wallace WA, Cave WT Jr. Echocardiographic characterization of the reversible cardiomyopathy of hypothyroidism. Am J Med 68: 675, 1980.

6) Steinberg AD. Myxedema and coronary artery disease - a comparative autopsy study. Ann Intern Med 68: 338, 1968.

7) Van Buren PC, Roberts WC. Cholesterol pericarditis and cardiac tamponade with congenital hypothyroidism in adulthood. Am Heart J 119: 697, 1990.

8) Hardisty CA, Naik DR, Munro DS. Pericardial effusion in hypothyroidism.
Clin Endocrinol 13: 349, 1980.

9) Alsever RN, Stjernholm MR. Cardiac tamponade in myxedema. Am J Med Sci 269: 117, 1975.

10) Smolar EN, Rubin JE, Avramides A, Carter AC. Cardiac tamponade in primary myxedema and review of the literature. Am J Med Sci 272: 345, 1976.

11) Das S, Lieberman AN, Schussler GC. Prolonged persistence of a large pericardial effusion and hemodynamic evidence of cardiac tamponade during treatment of myxedema. Clin Cardiol 5: 459, 1982.

12) Arvan S. Pericardial tamponade in a patient with treated myxedema. Arch Intern Med 143: 1983, 1983.

13) Kelly JK, Butt JC. Fatal myxedema pericarditis in a Christian Scientist. Am J Clin Pathol 86: 113, 1986.

14) Manolis AS, Varriale P, Ostrowski RM. Hypothyroid cardiac tamponade. Arch Intern Med 147: 1167, 1987.

15) Brawley RK, Vasko JS, Morrow AG. Cholesterol pericarditis: Considerations of its pathogenesis and treatment. Am J Med 41: 235, 1966.

16) Ford EJ, Bear PA, Adams RW. Cholesterol pericarditis causing cardiac tamponade. Am Heart J 122: 877, 1991.

17) Scheinberg P, Steat EA, Brannon ES Jr, Warren JV. Correlative observations on cerebral metabolism and cardiac output in myxedema. J Clin Invest 29: 1139, 1950.

18) MacKerrow SD, Osborn LA, Levy H, Eaton RP,Economou P. Myxedemaassociated cardiogenic shock treated with intravenous triiodothyronine. Ann Intern Med 117: 1014, 1992. 